\title{
The presence of three repeats in the 5 ' UTR region of thymidylate synthase (TS) is associated with increased TS mRNA expression in cultured human cancer cell lines in vitro
}

\author{
HIBA HAMMAD ${ }^{1}$, MALANCHA SARKAR $^{1}$, NIKHIL GUPTA $^{2}$, BACH ARDALAN $^{2}$ and POCHI R. SUBBARAYAN ${ }^{2}$ \\ Departments of ${ }^{1}$ Biology and ${ }^{2}$ Medicine, Division of Hematology and Oncology, \\ University of Miami Miller School of Medicine, Miami, FL 33136, USA
}

Received June 29, 2011; Accepted August 24, 2011

DOI: $10.3892 /$ or.2011.1469

\begin{abstract}
Thymidylate synthase (TS) gene contains 28-bp polymorphic sequence and 6-bp insert at the 5'- and 3'-untranslated region, respectively. We investigated the role of these two polymorphic traits on TS mRNA expression in nine different cultured human cancer cell lines in vitro. Three cell lines each were $2 R / 2 R, 2 R / 3 R$ and $3 R / 3 R$ genotypes. Six of the nine cell lines tested homozygous for the presence of 6-bp insert $(+6 /+6)$ and the rest three lacked this insert (-6/-6). TS expression analyses associated homozygous three repeats $(3 R / 3 R)$ to higher TS expression.
\end{abstract}

\section{Introduction}

5-fluorouracil (5-FU) is a uracil analog that has been used in the treatment of colorectal cancer (CRC) for over 40 years (1). Thymidylate synthase (TS) is an enzyme that methylates deoxyuridylate (dUMP), a metabolite of 5-FU, to deoxythymidylate (dTMP). TS is the only source of the de novo cellular thymidylate production (2). 5-FU is effective only when TS is completely inhibited by the formation of an inactive ternary complex composed of its metabolite, 5-FdUMP, TS and tetrahydrofolate (3). However, individual differences in TS levels exist. This variation in TS level is attributed to polymorphism in the 5'- and 3'-untranslated regions (UTR) of TS $(4,5)$ and a single nucleotide polymorphism (SNP) in the second repeat within the 5' UTR.

The 5' UTR of the TS mRNA contains a 28-bp sequence repeated two or three times (Fig. 1). Four or more repeats of

Correspondence to: Dr Pochi R. Subbarayan, Department of Medicine, Division of Hematology and Oncology, University of Miami Miller School of Medicine, FOX 431A, 1550 NW 10th Avenue, Miami, FL 33136, USA

E-mail: spochi@med.miami.edu

Key words: TS enhancer region, 3' UTR insertion, translation regulation, real-time PCR, thymidylate synthase mRNA level, genotypic analysis this segment have been reported but rare (6). This polymorphic region has been proposed to functionally regulate the translation of TS (4). Previous studies have found that the activity of a reporter gene linked to the 5'-terminal fragment of the TS gene with homozygous-triple tandem repeats $(3 R / 3 R)$ was 2.6 times higher than with homozygous-double tandem repeats $(2 \mathrm{R} / 2 \mathrm{R})$ or heterozygous repeats (2R/3R) (7). High TS levels have been associated with overcoming FdUMP-mediated blockage of TS and eventual 5-FU treatment failure (8). Consequently, this 28 -bp repeat was suggested to influence 5-FU treatment outcome (7).

A $\mathrm{G} \rightarrow \mathrm{C}$ SNP has also been identified at the 12th nucleotide position in the second repeat of $3 R$ alleles (9). This SNP alters the ability of transcriptional element USF proteins to bind within the repeat by effectively eliminating the USF E-Box. Without USF, the 3R construct has been shown to display a similar transcriptional activity as a $2 \mathrm{R}$ TS gene construct (10).

A search of the expression sequence tag (EST) database led to the discovery of a unique six nucleotide sequence (TTAAAG) in the 3' UTR of TS mRNA (11). In combination with the 5' UTR and SNP therein, this 6-bp insert is proposed to play a regulatory role in the TS expression (12). Functional investigations in vitro, suggested that the 6-bp insert may stabilize the TS mRNA transcript. Thus absence of the 6-bp (-6) insert may lead to low and the presence (+6) to high TS expression (5). Therefore, the regulatory role played by the TS polymorphic regions may affect treatment outcome in the CRC patients receiving 5-FU-based chemotherapy.

Based on the above finding, we hypothesize that: i) a combination of $3 R / 3 R$ and $+6 /+6$ genotypes will result in a higher TS mRNA level; ii) $2 \mathrm{R} / 2 \mathrm{R}$ and $-6 /-6$ genotypic combinations will end in low TS expression; iii) in heterozygous genotypes $(2 \mathrm{R} / 3 \mathrm{R} ;-6 /+6)$, varying levels of TS may be detected. In a nutshell, we anticipate the absence of the $6 \mathrm{bp}$ at the $3^{\prime}$ UTR region should result in less TS. We tested our hypothesis in cultured human cancer cell lines. Using a combination of PCR and restriction analysis, we determined the TS genotype in nine different human cancer cell lines. The TS expression in these cell lines were quantitated by real-time PCR. Finally, we compared the effect of different genotype combinations on TS expression. 


\section{-100 CCACCGCGCC ACTTGgCCTG CCTCCGTCCC GCCGCGCCAC TTGGCCTGCC TCCGTCCCGC CGCGCCACTT CGCCTGCCTC CGTCCCCGCC CCGCCGCGCC +1 ATGCCTGTGG CCGGCTCGGA GCTGCCGCGC CGGCCCTTGC CCCCCGCCGC}

Figure 1. Structure of the 5'-UTR region of human TS gene. The three 28-bp repeats and its relative position are shown. Bold type font, repeats 1 and 3; underline, repeat 2; italics underline within repeat 3, a variant of 28-bp region; bold underline italics, ATG start codon (17).

\section{Materials and methods}

Cell lines and culture conditions. The human pancreatic cancer cell lines MIA PaCa-2 (1420) and PANC-1 (1469), colorectal cancer cell lines HT29 and COLO 320HSR, T lymphocytes H9, lung cancer cell lines NCI-H23 and SHP-77 and the cervical cancer cell line HeLa were purchased from ATCC (Manassas, VA, USA). Osteosarcoma cell line 206 is a mitochondria-free derivative of 143B. All cells were maintained in the recommended culture medium and incubated at $37^{\circ} \mathrm{C}$ in a humidified $5 \% \mathrm{CO}_{2}$ atmosphere.

Chemicals and enzymes. Custom oligonucleotides for PCR and oligo(dT)16 for cDNA synthesis were procured from Sigma-Genosys, USA. All other reagent grade chemicals were purchased from local chemical suppliers.

Isolation of DNA and polymorphic analyses of the 5' UTR. The genomic DNA for polymorphic analyses was isolated from the cultured cell lines per rapid isolation of mammalian DNA (13). The TS 5' UTR region encoding the 28-bp repeat was synthesized using; TS5' sense 5'-GTGGCTCCTGCGTT TCCCCC-3' and TS5' anti-sense 5'-GCTCCGAGCCGGCC ACAGGCATGGCGCGG-3' as forward and reverse primers, respectively. The PCR product was electrophoresed on a $2 \%$ agarose gel. The fragments were visualized under UV illumination. Based on the PCR product length, the number of repeats in each TS allele was established. The composition of the PCR reaction mixture, thermal cycler settings, expected product length and agarose gel analysis were as described earlier $(14,15)$.

Restriction fragment length polymorphism (RFLP) analyses of the 3' UTR. The TS 3'-UTR fragment was synthesized by PCR. The PCR reaction mix contained $500 \mathrm{ng}$ of genomic DNA, $200 \mu \mathrm{mol}$ of dNTP mix, $300 \mathrm{nM}$ each of forward primer 5'-CAAATCTGAGGGAGTGAGT-3' and reverse primer 5'-CAGATAAGTGGCAGTACAGA-3' (11). The reaction was started by adding $25 \mu \mathrm{l}$ of high fidelity PCR master mix (Roche, USA) in a final volume of $50 \mu \mathrm{l}$. Initial denaturation was performed for $3 \mathrm{~min}$ at $95^{\circ} \mathrm{C}$. This was followed by incubation at $95^{\circ} \mathrm{C}$ for $30 \mathrm{sec}, 45 \mathrm{sec}$ each at $58^{\circ} \mathrm{C}$ and $72^{\circ} \mathrm{C}$, respectively, repeated 25 times. At the end, the reaction was incubated for an additional $5 \mathrm{~min}$ at $72^{\circ} \mathrm{C}$ and then chilled on ice. In the negative control, water replaced the DNA template. For positive control, DNA with known genotype was used.

For RFLP analysis, $10 \mu \mathrm{l}$ of the 3'-UTR PCR product was digested with the restriction enzyme DraI (Promega, USA) for

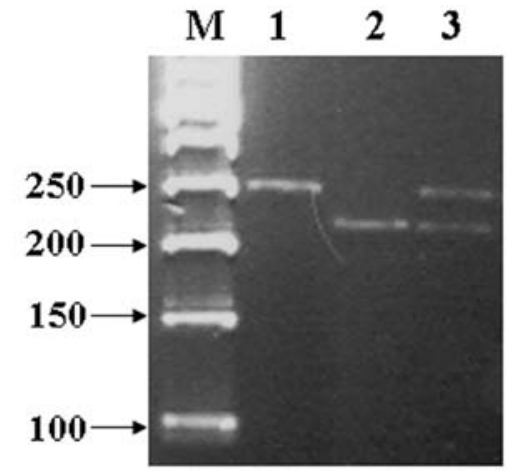

Figure 2. Agarose gel electrophoresis of 5'-UTR PCR products. The upstream region of human thymidylate gene was synthesized to analyze polymorphic repeats. PCR mixture $(5 \mu 1)$ was electrophoresed on $2 \%$ agarose 1000 gel impregnated with $0.5 \mu \mathrm{g}$ of ethidium bromide using $1 \mathrm{X}$ TBE buffer. It was electrophoresed at $10 \mathrm{~V} / \mathrm{cm}$ until the indicator dye-bromophenol blue ran to about $2 \mathrm{~cm}$ from the bottom of the gel. The DNA bands were visualized under UV illumination and photographed. Expected product lengths are about 208 bp for dimeric repeats. Presence of each additional polymorphic repeats increases the size by about 28 bp. Repeat 3 has an additional $6 \mathrm{bp}$ thus PCR products with three repeats are 242 bp $(208+28+6)$ long. Lane M, 50-bp DNA MW markers (Invitrogen, CA, USA); lane 1, 242 bp (trimeric repeats; 3R/3R); lane 2, 208 bp (dimeric repeats; 2R/2R); lane 3, 208 and 242 bp $(2 \mathrm{R} / 3 \mathrm{R})$.

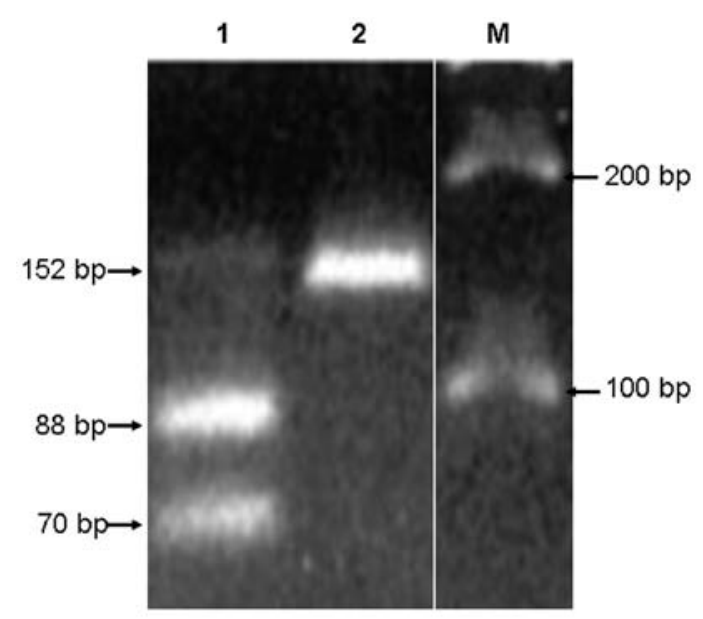

Figure 3. Agarose gel electrophoresis of PCR products. The 3'-UTR segment of human thymidylate gene was synthesized to analyze polymorphic repeats Restriction mixture $(10 \mu \mathrm{l})$ was electrophoresed on $3 \%$ agarose 1000 gel containing $0.5 \mu \mathrm{g}$ of ethidium bromide in $1 \mathrm{X}$ TBE buffer. The samples were electrophoresed at $10 \mathrm{~V} / \mathrm{cm}$ until the indicator dye-bromophenol blue ran to about $2 \mathrm{~cm}$ from the bottom of the gel. The DNA bands were visualized under UV illumination and photographed. Expected product lengths are about $158 \mathrm{bp}$ for fragment containing the 6-bp insert and 152 is short of $6 \mathrm{bp}$. Upon digestion with DraI 158-bp PCR product yields 88- and 70-bp fragments. Lane 1,88- and 70-bp fragment (+6/+6); lane 2, 152-bp PCR product (-6/-6); lane M, 50-bp DNA MW markers (Invitrogen).

$2 \mathrm{~h}$ at $37^{\circ} \mathrm{C}$ in a total reaction volume of $50 \mu \mathrm{l}$. The digestion was stopped by placing the tube on ice for $2 \mathrm{~min}$. DraI restriction mixture $(10 \mu \mathrm{l})$ was analyzed on $3 \%$ agarose gel. Undigested samples were loaded on adjacent wells. A single 158-bp band confirmed homozygous for 6-bp insertion $(+6 /+6)$. The DraI digest of the longer 158-bp PCR product yielded 70- and 88-bp 


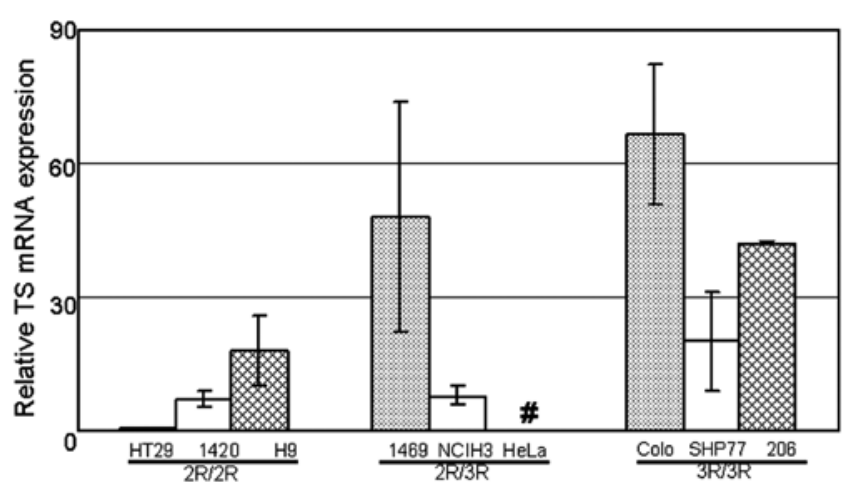

Figure 4. Relative TS mRNA expression in the selected human cancer cell lines. Total RNA was isolated using Tri-reagent (Sigma). Complementary DNA (cDNA) was synthesized using M-MLV (Promega) and dT16 primer. RT PCR was performed in a 96-well plate on GeneAmp Sequence Detection System 5700 (Applied Biosystem) with SYBR-Green PCR master mix, TS and $\beta$-actin primers. $\beta$-actin gene was used as the internal reference in calculating the mean normalized expression (MNE) of TS (19). Average of triplicate RT PCR assays is represented. "HeLa cell TS mRNA level is too low $(\mathrm{MNE}=0.105)$ to be visible in the $\mathrm{Y}$-axis scale used in this graph. Dotted and white bars represent $+6 /+6$ genotype. The hatched bars correspond to $-6 /-6$ genotype.

fragments (Fig. 3, lane 1). A 152-bp fragment unaffected by DraI digestion represented the $-6 /-6$ genotype (Fig. 3, lane 2).

Quantitative real-time PCR for TS mRNA expression. Total RNA isolation for quantitation, cDNA synthesis, real-time PCR setup and analyses were as described earlier (16).

Statistical analysis. Significant differences in TS mRNA expression level among different genotypes were calculated using one tailed Student's t-test. $\mathrm{P} \leq 0.05$ was considered significant.

\section{Results and Discussion}

The results of the genotypic and expression analyses performed in nine different human cancer cell lines are summarized in Table I and Fig. 4. The number of 28-bp tandem repeats in the 5 UTR was determined by PCR followed by size determination on a $2 \%$ agarose gel. The position of 28 -bp repeat with reference to the ATG start codon, sequence variations etc. are presented in Fig. 1 (17). A digital image of a $2 \%$ agarose gel showing the relative position of PCR fragments of two and three repeats is shown in Fig. 2. Colorectal cancer cell line HT29, pancreatic cancer cell line MIA PaCa-2 (1420) and T lymphocyte H9 are homozygous for two repeats $(2 \mathrm{R} / 2 \mathrm{R})$. Pancreatic cancer cell line PANC-1 (1469), lung cancer cell line NCI-H23 and cervical cancer cell line HeLa tested positive for heterozygous genotype (2R/3R). Colorectal cancer cell line COLO 320HSR, lung cancer cell line SHP-77, Osteosarcoma cell line 206 are homozygous for three repeats $(3 \mathrm{R} / 3 \mathrm{R})$.

The variations in the $3^{\prime}$ UTR was established by restriction fragment length polymorphism (RFLP). We used a combination of PCR, DraI restriction digestion and agarose gel analysis for fragment length determination. The 6-bp sequence introduced a DraI restriction site at the insertion point. Therefore,
Table I. Genotype of the 5'- and 3'-untranslated regions (UTR) of human TS gene and normalized TS mRNA level (expressed as mean normalized expression; MNE) in human cancer cell lines.

\begin{tabular}{|c|c|c|c|c|}
\hline \multirow[b]{2}{*}{ Cell line } & \multicolumn{2}{|c|}{ TS mRNA } & \multirow[b]{2}{*}{ 5' UTR } & \multirow[b]{2}{*}{ 3' UTR } \\
\hline & MNE & SD & & \\
\hline HT29 & $3.26 \mathrm{E}-04$ & $6.36 \mathrm{E}-06$ & $2 \mathrm{R} / 2 \mathrm{R}$ & $+6 /+6$ \\
\hline 1420 & 7.22E-03 & $1.71 \mathrm{E}-03$ & $2 \mathrm{R} / 2 \mathrm{R}$ & $+6 /+6$ \\
\hline H9 & $1.81 \mathrm{E}-02$ & $7.96 \mathrm{E}-03$ & $2 \mathrm{R} / 2 \mathrm{R}$ & $-6 /-6$ \\
\hline 1469 & 4.79E-02 & $2.59 \mathrm{E}-02$ & $3 \mathrm{R} / 2 \mathrm{R}$ & $+6 /+6$ \\
\hline NCIH23 & 7.92E-03 & 2.17E-03 & $3 R / 2 R$ & $+6 /+6$ \\
\hline HeLa & $1.05 \mathrm{E}-04$ & $4.95 \mathrm{E}-06$ & $3 \mathrm{R} / 2 \mathrm{R}$ & $-6 /-6$ \\
\hline Colo320HSR & $6.68 \mathrm{E}-02$ & $1.56 \mathrm{E}-02$ & $3 R / 3 R$ & $+6 /+6$ \\
\hline SHP77 & $2.01 \mathrm{E}-02$ & $1.09 \mathrm{E}-02$ & $3 \mathrm{R} / 3 \mathrm{R}$ & $+6 /+6$ \\
\hline 206 & $4.21 \mathrm{E}-02$ & $2.85 \mathrm{E}-04$ & $3 \mathrm{R} / 3 \mathrm{R}$ & $-6 /-6$ \\
\hline
\end{tabular}

upon digestion with $\operatorname{DraI}$, the PCR product with the 6-bp insert (158 bp) yielded 70- and 88-bp fragments (Fig. 3, lane 1). In the absence of the 6-bp sequence, no DraI-digested fragments were detected. Thus the presence of shorter 152-bp fragment was established (Fig. 3, lane 2). Our studies indicated human cancer cell lines HT29, COLO 320HSR, 1420, 1469, NCI-H23 and SHP-77 have 6-bp insertions in both the TS alleles. The 6-bp sequence was absent in both TS alleles of H9, HeLa and 206.

When studied in combination, the cell lines HT29 and 1420 that are homozygous for two repeats at its 5' UTR in TS gene also had 6-bp insertion at the 3 ' UTR $(2 R / 2 R ;+6 /+6)$. The third cell line $\mathrm{H} 9$ that is homozygous for two repeats lacked this 6-bp insertion $(2 \mathrm{R} / 2 \mathrm{R}$; -6/-6). Among the 5' UTR heterozygote's (2R/3R), cell lines 1469 and NCI-H23 were homozygous for 6-bp insertion at the 3 ' UTR $(2 R / 3 R ;+6 /+6)$, where as HeLa was homozygous for lack of this 6-bp sequence (2R/3R; -6/-6). Cell lines COLO 320HSR and SHP-77 that are homozygous for three repeats at the 5' UTR also had 6-bp insertion at the $3^{\prime}$ UTR in both the TS alleles $(3 R / 3 R ;+6 /+6)$. Osteosarcoma cell line 206 did not have this 6-bp sequence in the chromosomes $(3 R / 3 R ;-6 /-6)$. In this small sample size, none of the cell lines analyzed were heterozygous $(-6 /+6)$ at 3' UTR.

Studies have shown 5' UTR to influence TS transcription (10) and the 6-bpinsertion in the 3' UTR to increase the stability of TS mRNA (11). We measured TS mRNA level in these cell lines by quantitative real-time PCR. There were statistically significant differences in TS expression level among the three 5'-UTR genotypes. Compared to homozygous double ( $2 \mathrm{R} / 2 \mathrm{R})$ or heterozygous $(2 \mathrm{R} / 3 \mathrm{R})$ genotypes, relatively more TS mRNA was detected in homozygous triple repeat $(3 R / 3 R)$ background $(2 \mathrm{R} / 2 \mathrm{R}$ vs. $3 \mathrm{R} / 3 \mathrm{R}=\mathrm{p} \leq 0.00000245 ; 2 \mathrm{R} / 3 \mathrm{R}$ vs. $3 R / 3 R=p \leq 0.000134)$. There was no statistically significant difference in TS mRNA expression between homozygous for two repeats and heterozygous genotypes $(2 \mathrm{R} / 2 \mathrm{R}$ vs. $2 \mathrm{R} / 3 \mathrm{R}$ $=p \leq 0.1922)$. These observations are consistent with earlier reports $(7)$. 
Next we explored the influence of 6-bp sequence on TS mRNA expression. In this limited data set we did not find any association between TS mRNA level and different combinations of 5'- and 3'-UTR variants. In the homozygous for two repeats $(2 R / 2 R)$ genotype group, compared to the presence of the 6-bp sequence (HT29, 1420), cell line negative (H9) for this 6-bp sequence had more expression of TS mRNA ( $\mathrm{p} \leq 0.0015)$. Other than this single observation, our results contrast previously published data where in in vitro cloning studies linked the presence of 6-bp insertion to more stable transcripts, thereby more TS mRNA (5). However, this particular report did not include combinatory effect of 5'-UTR polymorphism. The current data were obtained by direct analysis of cultured cancer cells in vitro. The results may reflect cell to cell difference. Only one representative cell line each for the absence of 6-bp sequence with the three different 5'-UTR genotype combinations were tested. Increasing the number of cell lines with similar genotypic combination may improve statistical validity. Nevertheless, presently there are no reports on the effect of different genotypic combination on TS expression. Ideally such studies should be carried out using gene constructs integrated into a selected model cell line.

Besides the 5'- and 3'-UTR polymorphisms, Mandola et al, (9) reported the presence of an SNP in the 5' UTR. However, we did not include this variable in our analyses.

TS regulation can be classified as innate or induced. Polymorphism is innate whereas auto regulation is induced. As discussed earlier, the rate of TS transcription, translation and the transcript stability is regulated at many stages. Innately, if more TS is present as in the case of $3 R / 3 R$, 5-FU-based treatment may not be effective. Otherwise such treatments may result in high toxicity and early onset of 5-FU resistance. Therefore, it would be preferable to genotype patients for TS polymorphism to formulate an effective treatment cocktail. In the present scenario, 5-FU is now used in combination with other neoadjuvants like oxaliplatin, irinotecan, bevacizumab, and panitumab, rather than as a single agent. The relationship among tumor tissue TS polymorphic status, TS expression and treatment outcome is debatable $(10,18)$. These studies are based the results on only the polymorphic 5' UTR. There still exists an opportunity to analyze the relationship among different polymorphic combinations to TS expression in patient populations. An affirmative correlation between the polymorphism and TS level in this population may benefit vulnerable patient groups. Therefore, further well designed clinical studies are needed to understand the role of 5', 3' polymorphism, SNP in the 5' UTR and TS expression in cancer patient populations.

\section{Acknowledgements}

Technical help of undergraduate students Philip Lee, Alia Abdulla and others are appreciated. We thank Dr Ted Lampidis of our institution for the gift of osteosarcoma cell line 206.

\section{References}

1. Heidelberger C, Danenberg PV and Moran RG: Fluorinated pyrimidines and their nucleosides. Adv Enzymol Relat Areas Mol Biol 54: 58-119, 1983.

2. Peters GJ, Backus HH, Freemantle S, et al: Induction of thymidylate synthase as a 5-fluorouracil resistance mechanism. Biochim Biophys Acta 1587: 194-205, 2002.

3. Danenberg PV: Thymidylate synthetase - a target enzyme in cancer chemotherapy. Biochim Biophys Acta 473: 73-92, 1977.

4. Kaneda S, Takeishi K, Ayusawa D, Shimizu K, Seno T and Altman S: Role in translation of a triple tandemly repeated sequence in the 5'-untranslated region of human thymidylate synthase mRNA. Nucleic Acids Res 15: 1259-1270, 1987.

5. Mandola MV, Stoehlmacher J, Zhang W, et al: A 6-bp polymorphism in the thymidylate synthase gene causes message instability and is associated with decreased intratumoral TS mRNA levels. Pharmacogenetics 14: 319-327, 2004.

6. Marsh S, Ameyaw MM, Githang'a J, Indalo A, Ofori-Adjei D and McLeod HL: Novel thymidylate synthase enhancer region alleles in African populations. Hum Mutat 16: 528, 2000.

7. Pullarkat ST, Stoehlmacher J, Ghaderi V, et al: Thymidylate synthase gene polymorphism determines response and toxicity of 5-FU chemotherapy. Pharmacogenomics J 1: 65-70, 2001.

8. Johnston PG, Lenz HJ, Leichman CG, Danenberg KD, Allegra CJ, Danenberg PV and Leichman L: Thymidylate synthase gene and protein expression correlate and are associated with response to 5 -fluorouracil in human colorectal and gastric tumors. Cancer Res 55: 1407-1412, 1995.

9. Mandola MV, Stoehlmacher J, Muller-Weeks S, Cesarone G, Yu MC, Lenz HJ and Ladner RD: A novel single nucleotide polymorphism within the 5 tandem repeat polymorphism of the thymidylate synthase gene abolishes USF-1 binding and alters transcriptional activity. Cancer Res 63: 2898-2904, 2003.

10. Gusella M and Padrini R: G>C SNP of thymidylate synthase with respect to colorectal cancer. Pharmacogenomics 8: 985-996, 2007.

11. Ulrich CM, Bigler J, Velicer CM, Greene EA, Farin FM and Potter JD: Searching expressed sequence tag databases: discovery and confirmation of a common polymorphism in the thymidylate synthase gene. Cancer Epidemiol Biomarkers Prev 9: 1381-1385, 2000.

12. Grzybowska EA, Wilczynska A and Siedlecki JA: Regulatory Functions of 3'UTRs. Biochem Biophys Res Commun 288: 291-295, 2001.

13. Sambrook J and Russell DW: Molecular Cloning: A Laboratory Manual. 3rd edition. Cold Spring Harbor Laboratory Press, New York, 2001.

14. Villafranca E,Okruzhnov Y,Dominguez MA, et al: Polymorphisms of the repeated sequences in the enhancer region of the thymidylate synthase gene promoter may predict downstaging after preoperative chemoradiation in rectal cancer. J Clin Oncol 19: 1779-1786, 2001

15. Subbarayan PR, Sarkar M and Ardalan B: Isolation of genomic DNA from human whole blood. Biotechniques 33: 1231-1234, 2002.

16. Subbarayan PR, Lee K and Ardalan B: Arsenic trioxide suppresses thymidylate synthase in 5-FU-resistant colorectal cancer cell line HT29 in vitro re-sensitizing cells to 5-FU. Anticancer Res 30: $1157-1162,2010$.

17. Kaneda S, Nalbantoglu J, Takeishi K, Shimizu K, Gotoh O, Seno T and Ayusawa D: Structural and functional analysis of the human thymidylate synthase gene. J Biol Chem 265: 20277-20284, 1990.

18. Mauritz R, Giovannetti E, Beumer IJ, Smid K, van Groeningen CJ, Pinedo HM and Peters GJ: Polymorphisms in the enhancer region of the thymidylate synthase gene are associated with thymidylate synthase levels in normal tissues but not in malignant tissues of patients with colorectal cancer. Clin Colorectal Cancer 8: 146-154, 2009.

19. Subbarayan PR,Lima M and Ardalan B: Arsenic trioxide/ascorbic acid therapy in patients with refractory metastatic colorectal carcinoma: a clinical experience. Acta Oncol 46: 557-561, 2007. 